\title{
Multiallelic polymorphism of the cartilage collagen gene: no association with osteoarthrosis
}

\author{
Miikka Vikkula, Martti Nissilä, Eero Hirvensalo, Pekka Nuotio, Aarno Palotie, \\ Kimmo Aho, Leena Peltonen
}

\begin{abstract}
Objectives-To determine whether any of the type II collagen alleles are associated with generalised osteoarthrosis or osteoarthrosis of the finger joints in the genetically isolated Finnish population. Methods-Two patient cohorts with evidence for only primary osteoarthrosis and a cohort of healthy control subjects were selected from the Helsinki University Central Hospital and the Rheumatism Foundation Hospital in Finland. Forty one patients with primary generalised osteoarthrosis, 49 patients with osteoarthrosis of the finger joints, and 48 control subjects were included. Two markers of the type II collagen gene, a PvuII polymorphism and a VNTR polymorphism, were analysed from each subject.

Results-Four different alleles of the VNTR marker were observed and the relative risks associated with the different VNTR alleles varied between 0.39 and 1.24 among the patients with generalised osteoarthrosis and between 0.67 and 2.33 among the patients with osteoarthrosis of the finger joints. The PvuII polymorphism detected two different alleles and the associated relative risks were 0.82 and 1.82 for the patients with generalised osteoarthrosis, and 1.04 and 0.96 for the patients with osteoarthrosis of the finger joints.

Conclusions-A major predisposing allele of the type II collagen gene as the causative factor for osteoarthrosis could be excluded in this population. A spectrum of mutations associated with different alleles of this gene could not be excluded, however. Further, these two forms of cartilage disease can be caused by gene defects with reduced penetrance and the effect of such an allele is easily masked under the high frequency of normal alleles.
\end{abstract}

(Ann Rheum Dis 1993; 52: 762-764)

Osteoarthrosis is considered to be the most common articular disorder. The clinical phenotype can be explained by the progressive destruction of articular cartilage, but details of the molecular pathogenesis remain unclear. Osteoarthrosis disables millions of people in the world, the approximate prevalence rising from $4 \%$ in subjects between 18 and 24 years of age to as high as $85 \%$ in subjects between 74 and 79 years of age. ${ }^{1}$

Previous clinical family studies have shown that osteoarthrosis of the finger joints carries a strong genetic component based on an inheritance pattern comparable with an autosomal, sex influenced trait. The gene seems to be dominant in women, whereas in men its predisposing effect is recessive. ${ }^{2}$ In contrast, in the primary generalised form of the disease, the genetic predisposition seems more complex with features such as incomplete penetrance and polygenic inheritance. ${ }^{2}$ In some families, however, primary generalised osteoarthrosis is inherited like an autosomal dominant trait and it can be hypothesised that they represent an enrichment of one gene defect predisposing to generalised osteoarthrosis.

The major structural component of articular cartilage is type II collagen, encoded by one large gene (COL2A1) in chromosome 12. Owing to the major role of the type II collagen in the integrity of cartilage, the COL2A1 gene has served as a candidate gene in linkage analyses carried out in families with generalised osteoarthrosis. In 1989 we identified a close linkage (LOD score $3.21 ; \theta=0.0$ ) between the COL2A1 gene and generalised osteoarthrosis in two Finnish families. ${ }^{3}$ The linkage was established using two intragenic, biallelic polymorphisms of the gene, and was later confirmed with a multiallelic VNTR marker located about $1.5 \mathrm{~kb}$ from the $3^{\prime}$ end of the gene (figure). ${ }^{4} \mathrm{~A}$ similar finding was reported in one American family with an LOD score of 3.56 to three intragenic polymorphisms of the COL2A1 gene, but the phenotype of the patients in this family was distinctly different and included mild symptoms of chondrodysplasia associated with signs of primary generalised osteoarthrosis. ${ }^{5}$ A mutation was thereafter characterised in the COL2A1 gene of the patients of this family, and the same mutation has also been identified in two additional families out of seven studied. ${ }^{67}$

To evaluate whether the COL2A1 gene defects had more general significance in the aetiopathogenesis of osteoarthrosis we tested the association between the COL2A1 gene and osteoarthrosis in the genetically isolated Finnish population. The patients were carefully selected to represent distinct clinical 


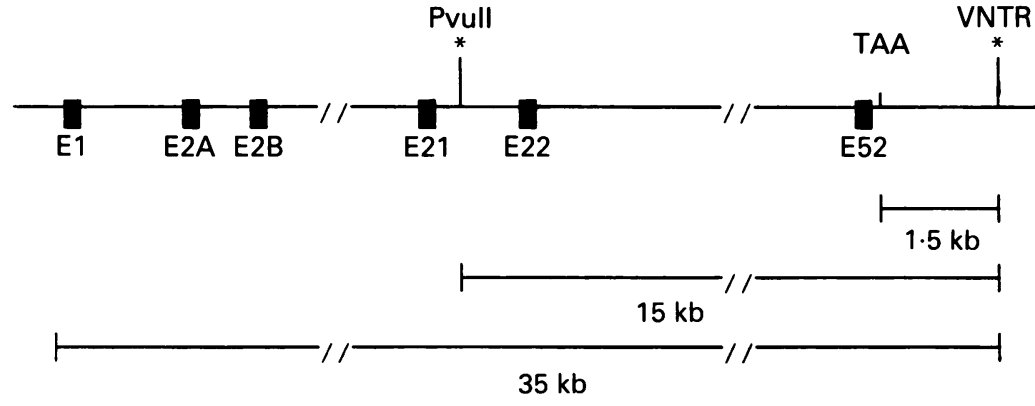

Schematic presentation of the type II procollagen (COL2A1) gene with the two polymorphisms (PvuII and VNTR) used in the analyses. $E=$ exon; TAA=the stop codon.

subtypes of osteoarthrosis: primary generalised osteoarthrosis or osteoarthrosis of the finger joints.

\section{Patients and methods}

The patients with primary generalised osteoarthrosis were selected from the Rheumatism Foundation Hospital (Heinola, Finland) and from the Helsinki University Central Hospital. Three of the authors (EH, MN, and PN) selected 41 patients among patients sent to the hospitals for possible arthroplasia. The following criteria for primary generalised osteoarthrosis were used: (a) onset of symptoms before 50 years of age; $(b)$ radiographic signs of osteoarthrosis identified in more than one weightbearing joint; $(c)$ no evidence of trauma, vascular abnormalities, infection, surgery, or other factors or conditions predisposing to secondary generalised osteoarthrosis found in carefully examined hospital records or from anamnestic information; and (d) erythrocyte sedimentation rate and serological tests for rheumatoid factor ruled out inflammatory synovitis. Forty nine patients with osteoarthrosis of the finger joints were selected by the same workers. These patients, originally sent to the hospital for evaluation of possible rheumatoid arthritis, all had non-traumatic Heberden's nodes and only the joints of the hands were affected (i.e. carpal, carpometacarpal, metacarpophalangeal, and interphalangeal joints). All the control subjects were selected by PN from patients in a general hospital (Heinola, Finland); they were over 60 years of age and did not have joint symptoms. They were all confirmed as having no radiographic evidence of osteoarthrosis.

Blood samples were collected from all 138 subjects and DNA was extracted according to standard methods. All three subgroups (generalised osteoarthrosis, osteoarthrosis of the finger joints, controls) were screened for two polymorphisms of the COL2A1 gene 15 $\mathrm{kb}$ apart from each other (figure); one biallelic intragenic PvuII marker and one multiallelic VNTR marker adjacent to the 3 ' end of the gene. ${ }^{4}$ These polymorphisms represent nucleotide changes which themselves do not alter the transcription/translation product of the gene. The polymerase chain reaction was applied to amplify the regions of the markers from the genomic DNA of the subjects. The primers used for the PvuII marker were
GGGAAGTGGAGTCCTTGTGG and TTGCCGGGAGCACCCTAAGG, and the polymerase chain reaction was run at $94^{\circ} \mathrm{C}$ for one minute, $58^{\circ} \mathrm{C}$ for one minute, and $72^{\circ} \mathrm{C}$ for one minute for 30 cycles. An additional step at $72^{\circ} \mathrm{C}$ for 10 minutes was attached to the last cycle. After PvuII restriction digestion the amplification products were run on $1 \%$ agarose gel. If the amplified allele included the PvuII restriction site the 331 base pair long amplification product was digested into two fragments, 211 and 120 base pairs long. In heterozygotes all three fragments could be observed. Details of the detection of the alleles of the VNTR marker are given in Vikkula et $a .^{4}$

To calculate the differences in the allelic distribution of the three subgroups we used the ASSOC and CONTING options (versions $2 \cdot 30$ and 2.40 respectively) of the LINKAGE UTILITY programs by Dr Jürg Ott. CONTING is a contingency table calculating the contribution to the $\chi^{2}$ value of each cell separately. We calculated the $p$ values for the differences in the allelic distribution individually for three sets: generalised osteoarthrosis versus controls, osteoarthrosis of the finger joints versus controls and generalised osteoarthrosis versus osteoarthrosis of the finger joints. The ASSOC program compares the set of genotypes of one subgroup with another also using the $\chi^{2}$ test. These analyses were performed for the same three sets. We also used the RERI option (version 2.2), which calculates the relative risks and $95 \%$ confidence limits using the formula of Mantel and the formula of Haldane, to analyse the relative risks for each individual COL2A1 allele.

\section{Results and discussion}

Tight linkage to the COL2A1 gene has so far been identified in two Finnish families with early onset primary generalised osteoarthrosis and without any evidence for other inherited cartilage disorders. ${ }^{3}$ The Finnish population is a well known example of a genetically isolated gene pool and this could explain the observed familial enrichment of this genetically complex disease, the families most probably representing enrichment of one predisposing gene. Consequently, we wanted to pursue the possibility that an association between generalised osteoarthrosis or osteoarthrosis of the finger joints and the COL2A1 gene could also be identified more generally in this population.

The distribution of the alleles of the biallelic PruII marker and the multiallelic VNTR marker of the COL2A1 gene showed no statistically significant differences between the three groups (table 1). The individual genotypes of the two polymorphisms did not show any deviations among these clinically carefully examined groups (data not shown). Relative risks for individual alleles were also determined (table 2). Wide deviations observed in $95 \%$ confidence intervals are most probably explained by the limited number of subjects 
Table 1 Observed numbers of COL2A1 alleles

\begin{tabular}{lccc}
\hline Allele & $G O A^{*}$ & $F O A^{*}$ & Controls \\
\hline 3' VNTRt & & & \\
1 & 0 & 3 & 1 \\
2 & 28 & 23 & 30 \\
3 & 47 & 57 & 50 \\
4 & 7 & 15 & 15 \\
PvuII & & & \\
1 & 43 & 57 & 55 \\
2 & 39 & 41 & 41 \\
\hline
\end{tabular}

${ }^{\star} \mathrm{GOA}=$ generalised osteoarthrosis; FOA=osteoarthrosis of the finger joint.

tp Values: $\mathrm{GOA} / \mathrm{FOA}=0.11 ; \quad \mathrm{FOA} / \mathrm{Controls}=0.50 ; \mathrm{GOA} /$ Controls $=0 \cdot 39$. fp Values: GOA$/ \mathrm{FOA}=0.44 ; \quad$ FOA/Controls $=0.90 ; \quad \mathrm{GOA}$
Controls $=0.52$.

Table 2 Relative risks of the COL2A1 alleles

\begin{tabular}{cll}
\hline Allele & Relative risk & 95\% Confidence interval \\
\hline $\begin{array}{c}\text { 3. VNTR } \\
\text { GOA* }\end{array}$ & & \\
1 & $0.39 \dagger$ & 0.03 to 4.33 \\
2 & 1.14 & 0.61 to 2.12 \\
3 & 1.24 & 0.69 to 2.21 \\
4 & 0.50 & 0.21 to 1.29 \\
FOA & & 0.42 to 13.04 \\
1 & $2.33 \dagger$ & 0.36 to 1.27 \\
2 & 0.67 & 0.73 to 2.24 \\
3 & 1.28 & 0.46 to 2.08 \\
4 & 0.98 & \\
PvuII & & 0.46 to 1.48 \\
GOA & & 0.68 to 2.18 \\
1 & 0.82 & 0.59 to 1.82 \\
2 & 1.22 & 0.55 to 1.70 \\
FOA & 1.04 & \\
1 & 0.96 &
\end{tabular}

$\star$ GOA=generalised osteoarthrosis; $\mathrm{FAO}=$ osteoarthrosis of the finger joints.

tHaldane's formula, $[(2 a+1)(2 d+1)] /[(2 b+1)(2 c+d)]$, was used.

analysed. The results provide no evidence for increased risk of either generalised osteoarthrosis or osteoarthrosis of the finger joints associated with any of the COL2A1 alleles, however. Taken together these data rule out the possibility of the COL2A1 gene being the major predisposing gene either for primary generalised osteoarthrosis or osteoarthrosis of the finger joints in this population. One earlier study from the British population reported 'limited association' (all p values being $>0 \cdot 2$ ) between generalised osteoarthrosis and the COL2A1 gene. The analysis was performed with patients representing generalised osteoarthrosis and osteoarthrosis of the finger joints, complicating direct comparisons of these two studies. ${ }^{8}$

We can conclude that primary osteoarthrosis is linked to the COL2A1 gene in some familial forms of the disease, ${ }^{357}$ but no such association can be identified at the population level either between generalised osteoarthrosis or osteoarthrosis of the finger joints and the COL2A1 locus. Owing to the limitations of association analyses, mutations linked to common alleles of analysed markers and existing at low frequency cannot be identified at the population level. Therefore we cannot exclude the possibility that some of the sporadic cases would still be caused by mutations in the COL2A1 gene. At the population level, however, other genes, coding, for example, for other cartilage proteins, should be looked for to pursue the predisposing genetic components of generalised osteoarthrosis and osteoarthrosis of the finger joints.

The authors thank Professor Seppo Sarna for his valuable comments on the statistical analyses. This work was supported by grants from the Academy of Finland, the Finnish Cultura Foundation, the Paulo Foundation, the Research and Science Foundation of Farmos, the Rheumatism Research Foundation of Finland, the Yrjö Jahnsson Foundation, and the Concerted Action on Heritable Connective Tissue Disorders of the European Communities.

1 Masi A T, Medsger T A Jr. Epidemiology of the rheumatic diseases. In: McCarty D J, ed. Arthritis and allied diseases. In: McCarty D J, ed. Arthritis and
conditions. London: Lea and Febiger, 1989: 16-54.

2 Hough A J Jr, Sokoloff L. Pathology of osteoarthritis. In McCarty D J, ed. Arthritis and allied conditions. London: Lea and Febiger, 1989: 1571-9

3 Palotie A, Väisänen P, Ott J, et al. Predisposition to familial osteoarthrosis linked to type II collagen gene. Lancet 1989; i: $924-7$

4 Vikkula M, Palotie A, Ritvaniemi P, et al. Early onset osteoarthritis linked to the type II procollagen gene: detailed clinical phenotype and further analyses of the gene. Arthritis Rheum 1993; 36: 401-9.

5 Knowlton R G, Katzenstein P L, Moskowitz R W, et al. Genetic linkage of a polymorphism in the type II procollagen gene (COL2A1) to primary osteoarthritis associated with mild chondrodysplasia. $N$ Engl $f \mathrm{Med}$ 1990; 322: 526-30.

6 Ala-Kokko L, Baldwin C T, Moskowitz R W, Prockop D $\mathrm{J}$. Single base mutation in the type II procollagen gene (COL2A1) as a cause of primary osteoarthritis associated with a mild chondrodysplasia. Proc Natl Acad Sci USA 1990; 87: 6565-8.

7 Moskowitch R W, Pun Y, Lei S T, Haggi M. ARG ${ }_{519}-\mathrm{CYS}$ mutation in COL2A1 defines a new subset of osteoarthritis. Arthritis Rheum 1992; 35(suppl 9): 35 .

8 Priestley L, Ferguson C, Ogilvie D, et al. A limited association of generalized osteoarthritis with alleles at the type II collagen locus: COL2A1. Br f Rheumatol 1991; 30: $272-5$. 